\title{
Development of a Physical Separation Route for the Concentration of Base Metals from Old Wasted Printed Circuit Boards
}

\author{
Pedro Jorge Walburga Keglevich de Buzin ${ }^{1}$, Weslei Monteiro Ambrós ${ }^{2} \mathbb{D}$, Irineu Antônio Schadach de Brum ${ }^{2} \mathbb{D}$, \\ Rejane Maria Candiota Tubino ${ }^{1}$, Carlos Hoffmann Sampaio ${ }^{3, * \mathbb{D}}$ and Josep Oliva Moncunill ${ }^{3}$ (D) \\ 1 Environmental Metallurgy Laboratory, Federal University of Rio Grande do Sul, \\ 9500 Bento Gonçalves Avenue, Porto Alegre 91501-970, Brazil; pedrobuzin@gmail.com (P.J.W.K.d.B.); \\ rejane.tubino@gmail.com (R.M.C.T.) \\ 2 Mineral Processing Laboratory, Federal University of Rio Grande do Sul, 9500 Bento Gonçalves Avenue, \\ Porto Alegre 91501-970, Brazil; weslei.ambros@ufrgs.br (W.M.A.); irineu.brum@ufrgs.br (I.A.S.d.B.) \\ 3 Departament d'Enginyeria Minera, Industrial i TIC, Escola Politècnica Superior d'Enginyeria de Manresa, \\ Universitat Politècnica de Catalunya, Av. Bases de Manresa 61-63, 08242 Manresa, Spain; josep.oliva@upc.edu \\ * Correspondence: carlos.hoffmann@upc.edu
}

check for updates

Citation: de Buzin, P.J.W.K.; Ambrós, W.M.; de Brum, I.A.S.; Tubino, R.M.C.; Hoffmann Sampaio, C.; Oliva Moncunill, J. Development of a Physical Separation Route for the Concentration of Base Metals from Old Wasted Printed Circuit Boards. Minerals 2021, 11, 1014. https:// doi.org/10.3390/min11091014

Academic Editor: Chiharu Tokoro

Received: 29 August 2021

Accepted: 17 September 2021

Published: 18 September 2021

Publisher's Note: MDPI stays neutral with regard to jurisdictional claims in published maps and institutional affiliations.

Copyright: (c) 2021 by the authors. Licensee MDPI, Basel, Switzerland. This article is an open access article distributed under the terms and conditions of the Creative Commons Attribution (CC BY) license (https:// creativecommons.org/licenses/by/ $4.0 /)$.

\begin{abstract}
Wastes from old electronic devices represent a significant part of the electronic scrap generated in developing countries, being commonly sold by collectors as low-value material to recycling hubs abroad. Upgrading the quality of this waste type could drive the revenue of recyclers, and thus, boost the recycling market. On this basis, this study investigated the possibility of concentrating metals from old wasted printed circuit boards through a physical separation-based route. Preparation of samples comprised fragmentation, size classification, density, and magnetic separation steps, followed by chemical and macro composition analysis. $\mathrm{Cu}, \mathrm{Al}, \mathrm{Fe}$, and $\mathrm{Sn}$ constituted the major metals encountered in the scraps, including some peak concentrations of $\mathrm{Zn}, \mathrm{Sb}, \mathrm{Pb}, \mathrm{Ba}$, and $\mathrm{Mn}$. Four distinct concentrate products could be obtained after suitable processing: (a) a light fraction composed of plastics and resins; (b) an aluminum concentrate; (c) a magnetic material concentrate, containing mainly iron; (d) a final concentrate containing more than $50 \%$ in mass of copper and enriched with nonferrous metals. Preliminary evidence showed that further processes, like the separation of copper wires through drumming, can potentially improve the effectiveness of the proposed processing circuit and should guide future works.
\end{abstract}

Keywords: old scrap; electronic wastes; physical separation; recycling; printed circuit boards

\section{Introduction}

The growing global demand for metals stands in contrast to the current scenario of decreasing ore grades, more complex mineralogy, and more intense environmental concerns related to the extractive sector. In parallel, increasing amounts of waste are being generated as the automotive and electronic devices industries expand their activities. Expected advances in sustainable energy technologies and the boom of automation leveraged by the industry 4.0 transition should increase even more both the demand for metals and the generation of their respective waste products. In this context, the term "urban mining" [1] has emerged as a concept that goes beyond recycling as a mere ecological activity, but rather as a necessity aimed at maximizing the use of non-renewable resources such as metals through technologies that minimize environmental impacts.

Because they include non-ferrous and precious metals such as gold, copper, cobalt, and rare earths in their composition, wastes from electrical and electronic equipment (WEEE) are among the main targets of urban mining. WEEEs are also notable for being the waste stream with the highest growth rate worldwide, up to $5 \%$ per year. However, of the approximately 50 million tons generated annually, it is estimated that only 13\% is 
effectively recycled $[2,3]$. Developing nations have shown increasing per capita generation of electronic scrap, although still presenting poor recycling rates. Brazil, for instance, recycles only about $4 \%$ of its total solid waste generated [4].

Metals such as copper and precious $(\mathrm{Au}, \mathrm{Ag}$, etc.) are mainly embedded in printed circuit boards (PCBs), making them a fundamental constituent of WEEEs. PCB weight contributions range from about $12 \%$ in liquid crystal displays (LCDs) to more than $21 \%$ in mobile phones and are typically composed of about $40 \%$ metals, 30\% plastics, and 30\% ceramic compounds [5-7]. The content of different metals in PCBs varies according to device type and age. For instance, PCBs from older devices, such as cathode ray tube (CRT) monitors, contain considerable amounts of $\mathrm{Cu}, \mathrm{Fe}, \mathrm{Sn}$, and $\mathrm{Pb}$ used in soldering and lead frames [3]. PCBs currently make up most of the electronic waste globally recycled since they are relatively rich in copper and precious metals, especially gold.

Recycling of PCBs involves the initial stages of physical separation (dismantlement, shredding, size classification, gravity concentration, magnetic separation, etc.), whose primary focus is to separate the metallic from the non-metallic fraction [8,9]. The metal-rich concentrate thus generated is then treated through hydrometallurgical or pyrometallurgical processing routes [10]. Nowadays, pyrometallurgical plants are the main recycling centers for most WEEE, involving high operational and energy costs [3]. Thus, they require a constant supply of material with stable composition and preferably containing high contents of precious metals. These restrictions favor limiting the recycling of electronic wastes to only a few large metallurgical companies, whose plants concentrate in specific regions of the globe. Among these, one can cite Aurubis (Hamburg, Germany) [11], Glencore (Toronto, Ontario, Canada) [12], and Umicore (Brussels, Belgium) [13]. Although each of them displays specific features in their extractive routes, the processing basically involves adapting conventional pyrometallurgical operations of non-ferrous metals, particularly copper, nickel, and lead, to the context of electronic wastes. Because they are easier to control, operate at lower temperatures, and generate fewer emissions, hydrometallurgical routes have been pointed out as a trend in future WEEE processing [3]. However, the generation of large quantities of wastewaters contributes to their still comparatively lower use.

Current research on recycling of PCBs and, more generally, electronic wastes have focused on the use of refined processing operations, such as microwave pyrolysis [14], slurry electrolysis [15], and vacuum-gasification-condensation [16], to cite a few. Bio-metallurgical techniques such as bioleaching are receiving special attention in recent years, as they have the potential to overcome typical limitations of pyro- and hydrometallurgical processes, such as high operational costs and production of toxic gases and wastewaters [10,17]. Their long-scale applications for recycling, however, are still germinal. On the other hand, fewer studies have been dedicated to investigating improvements in physical separation technologies capable of generating high purity concentrates (or even pure metals) at minimal economic and environmental costs. Nevertheless, some physical separation techniques, such as gravity [18-20] and electrostatic [21,22] separation and froth flotation [23-25], have received some attention. Among these, gravity separation processes stand out for their relatively low costs and technical versatility, favored by the fact that electronic wastes have individual components of varied densities, from about $0.9 \mathrm{~g} / \mathrm{cm}^{3}$ for plastic substrates to $11.3 \mathrm{~g} / \mathrm{cm}^{3}$ for lead frames.

The improvement of physical separation routes for recycling electronic wastes is particularly interesting for processing old and low value scraps whose precious metal content is relatively low, despite still having significant amounts of valuable metals, especially non-ferrous. TVs, monitors, and printer boards fall into this category, which despite usually having less than 20 ppm of gold (versus 200 ppm in PC-boards), might contain up to 12\%, $15 \%$, and $30 \%$ of $\mathrm{Cu}, \mathrm{Al}$, and Fe by weight, respectively [3]. Old, discarded PCBs can also have up to $5 \% \mathrm{~Pb}$ in solders [26]. Still, when all the printed circuit board assembly (PCBA,) consisting of resistors, capacitors, transformers, and wires, is considered, the content and variety of metals can be considerable higher. That said, it is worth mentioning that old 
and low value-added electronic scraps still make up a large fraction of the WEEE generated in developing countries, which in some cases also receive old WEEE as a donation from developed countries [27]. In this sense, the implementation of low capital cost and pollution-free recycling methods focusing on physical separation of electronic wastes is not only technically possible, as recently showed by Zhu et al. [28], but can be decisive for the income and subsistence of small- and medium-scale recyclers.

Within the context above, and as part of an ongoing project concerned with the development and improvement of physical separation operations for WEEE recycling, this paper aims to examine the feasibility of recovering metals and generating metal concentrates through the application of physical separation techniques in wasted printed circuit boards assemblies (PCBAs). Special focus is given to gravity separation processes.

\section{Materials and Methods}

\subsection{Materials}

The samples used consisted of wasted PCBAs obtained from a recycling center located in Porto Alegre city, Brazil. The material was composed of old electronic scrap from TV boards, washing machines, stereos, power supplies, etc., characterized by having low precious metal contents compared to other PCBs, and still assembling other pieces, such as voltage transformers, flyback transformers, aluminum electrolytic capacitors, and ferrite cores. However, the samples were collected without the main power supply voltage converter (Fe-Si alloy), removed upon receipt at the recycling plant. Figure 1a shows a picture of the samples used.

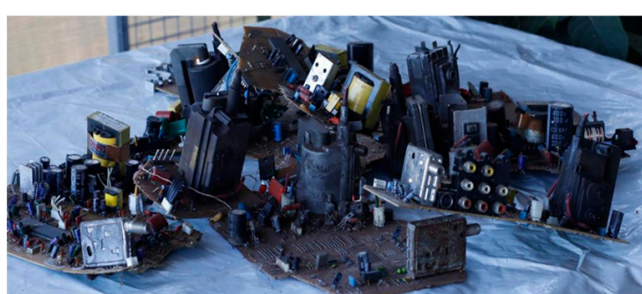

(a)

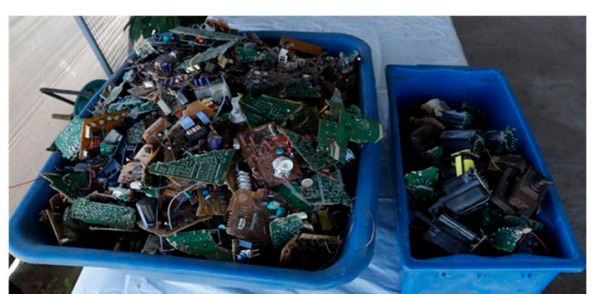

(b)

Figure 1. (a) Raw PCBAs samples. (b) Samples after dismantlement: PCBs (left) and voltage and flyback transformers (right).

The samples were dismantled into two fractions: (a) voltage, flyback, and ferrite core transformers and (b) remaining PCBs. The removal of the voltage transformers and flybacks was mainly because they were composed of iron-based alloys, being not suitable for fragmentation in the comminution equipment used. Ferrite transformers were separated from PCBs because they consisted basically of a copper coil and a ferrite core, a fragile material of easy fragmentation. The processing of the transformers was not addressed in the current study. The amount of analyzed material, after transformers removal, totaled approximately $17 \mathrm{~kg}$ of PCBs (Figure 1b).

\subsection{Samples Preparation}

Characterization of the PCI samples involved fragmentation, size classification, and density separation into different fractions, whose compositions were then analyzed at the macroscopic and elemental levels (Figure 2). Further composition analysis of the densest fraction obtained in the essays was also carried out and is described in detail in Section 3.2. The fragmentation step was performed in a knife and hammer mill, model Trapp-TRF 700, shown in Figure 3. The mill has steel knives for the initial grinding of the feed followed by comminution with a set of steel hammers arranged on four shafts (Figure 3a). Different from the original specification (7.4 HP and $3600 \mathrm{RPM})$, milder milling conditions were used (3.0 HP and $2000 \mathrm{RPM}$ ) to ensure the dismantling effect (liberation of metals from the substrate) rather than promoting excessive fragmentation and generation of fines, which 
are generally more difficult to separate by physical methods. The mill discharge rate was about $0.5 \mathrm{~kg} / \mathrm{min}$. A $12-\mathrm{mm}$ aperture sieve fixed near the outlet duct allowed the easy discharge of dismantled material, inhibiting over-comminution and ensuring that all material discharged from the mill had a particle size below $12 \mathrm{~mm}$. Preliminary tests with similar PCBs revealed the occurrence of indirect segregation of thin sheets containing aluminum generated by the mechanical disaggregation of the internal winding of larger electrolytic capacitors. The segregation occurred due to the air current generated during the rotation of the mill shafts, which tended to disperse the sheets after mill discharge. Thus, during testing, an air blower was positioned perpendicularly to the mill outlet duct to separate the thin sheets from the discharged material (Figure $3 b$ ).

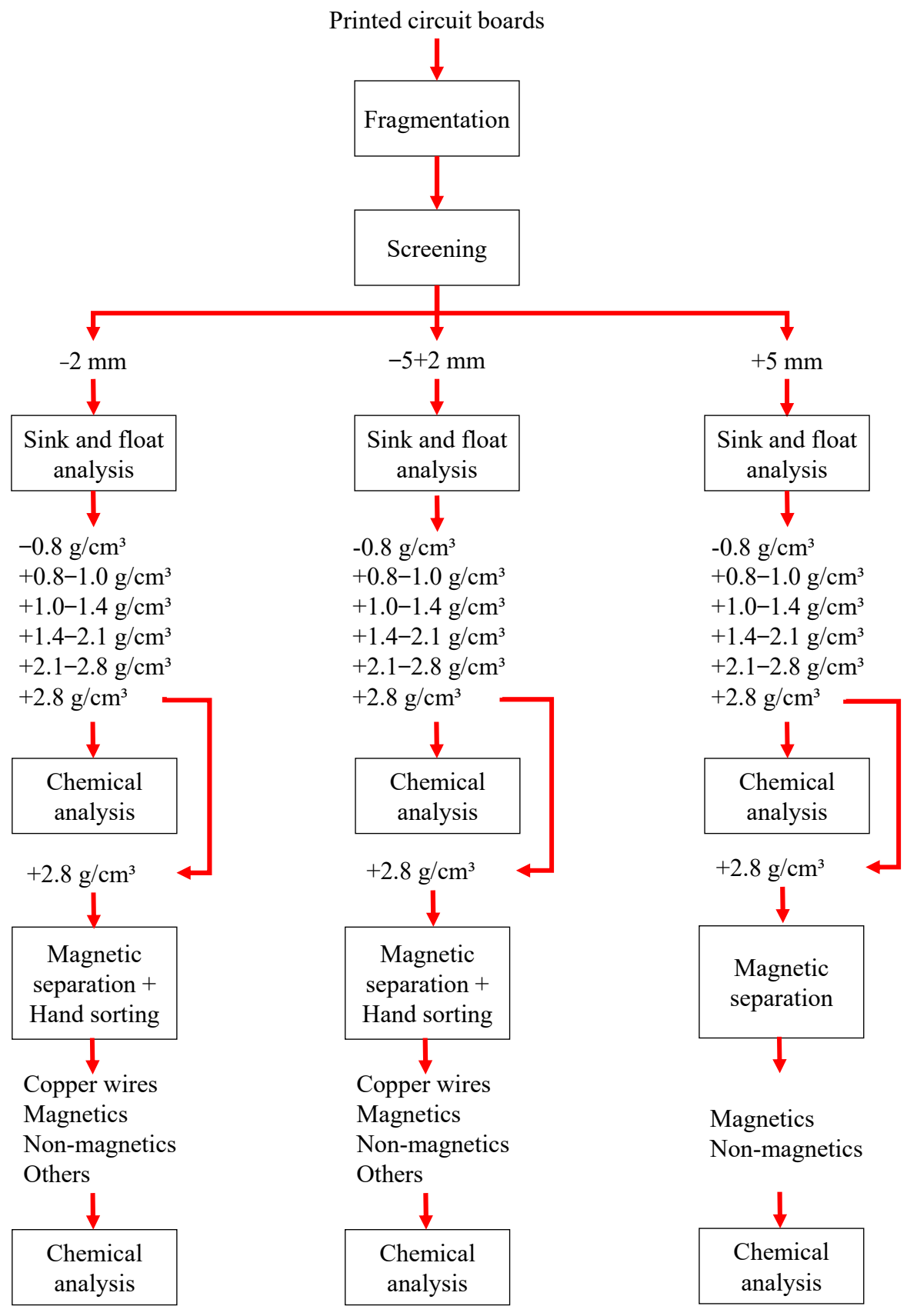

Figure 2. Scheme adopted for wasted PCB characterization. The composition analysis of the $+2.8 \mathrm{~g} / \mathrm{cm}^{3}$ fraction is described in more detail in Section 3.2. 


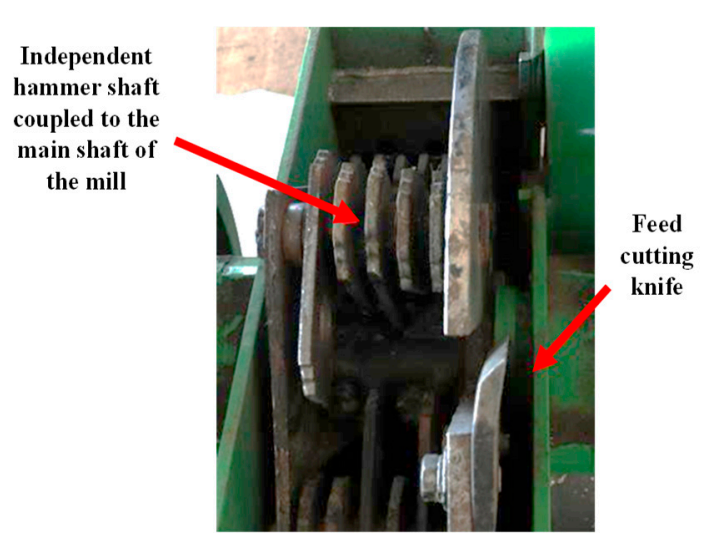

(a)

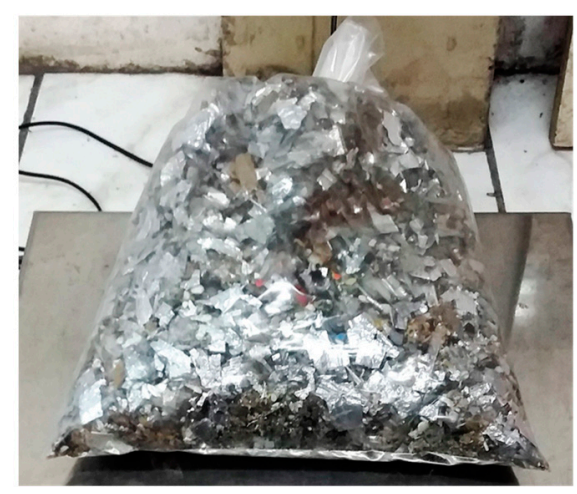

(b)

Figure 3. (a) Detail of the mill shafts. (b) Collected aluminum-containing thin sheets.

The fragmented material was classified by screening into three particle size fractions: (a) a coarse fraction of $+5 \mathrm{~mm}$; (b) an intermediate fraction, in the range of $-5+2 \mathrm{~mm}$; and (c) a d $\leq 2 \mathrm{~mm}$ fine fraction. Sink and float tests according to ASTM D4371-06 were subsequently carried out in each size fraction to determine the distribution of metals over different density ranges. Sink and float tests consist of the introduction of samples in liquids of incremental densities, collecting the float or the sink aliquots of each separating density, which are individually washed, dried, weighed, and chemically analyzed. Thus, it allows assessing the density distribution profile of the sample, the feasibility of enrichment through density separation methods as well as the suitable separating density [29,30]. The heavy liquids used consisted of mixtures of bromoform $\left(\mathrm{CHBr}_{3} ; 2.89 \mathrm{~g} / \mathrm{cm}^{3}\right.$ density), perchloroethylene $\left(\mathrm{C}_{2} \mathrm{Cl}_{4} ; 1.62 \mathrm{~g} / \mathrm{cm}^{3}\right.$ density), xylene $\left(\mathrm{C}_{8} \mathrm{H}_{10} ; 0.87 \mathrm{~g} / \mathrm{cm}^{3}\right.$ density), and ethanol $\left(\mathrm{C}_{2} \mathrm{H}_{5} \mathrm{OH} ; 0.78 \mathrm{~g} / \mathrm{cm}^{3}\right.$ density) at densities of $0.8,1,1.4,2.1$, and $2.8 \mathrm{~g} / \mathrm{cm}^{3}$. PCBs samples were so fractionated in the following density ranges: $-0.8 \mathrm{~g} / \mathrm{cm}^{3},-1+0.8 \mathrm{~g} / \mathrm{cm}^{3}$, $-1.4+1 \mathrm{~g} / \mathrm{cm}^{3},-2.1+1.4 \mathrm{~g} / \mathrm{cm}^{3},-2.8+2.1 \mathrm{~g} / \mathrm{cm}^{3}$, and $+2.8 \mathrm{~g} / \mathrm{cm}^{3}$. Each fraction was then individually analyzed to determine the content of metals, as described below.

\subsection{Chemical Characterization}

All subsamples obtained in the preparation step were analyzed using Inductively Coupled Plasma Optical Emission Spectrometry (ICP-OES, Shimadzu, Kyoto, Japan). For this purpose, a representative portion of $100 \mathrm{~g}$ of each subsample was obtained by riffling (subsample whole mass was considered in the case of subsamples less than $100 \mathrm{~g}$ ). Each sample was then comminuted for $4 \mathrm{~h}$ in a laboratory ball mill $(30-40 \% 25 \mathrm{~mm}$ balls filling in a $200 \times 300 \mathrm{~mm}$ drum rotating at $40 \mathrm{RPM}$ ) and weighed before and after the process in order to identify the occurrence of oxidation. Weight variation was negligible or even negative in a few cases (probably due to small losses during handling) so that no oxidation of the samples was assumed to not occur. The samples were subsequently riffled to obtain a $10 \mathrm{~g}$ aliquot for digestion. This mass is about $10 \times$ larger than the usual in the mineral and metals digestion practice [31], but it was adopted to improve the representativeness of aliquots. Each weighed $10 \mathrm{~g}$ sample was heated to $90-105^{\circ} \mathrm{C}$ with $200 \mathrm{~mL}$ of aqua regia (mixture of concentrated $\mathrm{HCl}$ and $\mathrm{HNO}_{3}$ in a molar ratio of 1:3) for three hours. Then, each solution was diluted to volume with distilled water and paper-filtered. The collected solutions from each sample were transferred to $1000 \mathrm{~mL}$ volumetric flasks and diluted to volume with distilled water, from which a $50 \mathrm{~mL}$ aliquot was separated for ICP-OES analysis.

\section{Results}

\subsection{General Characterization}

Table 1 shows the distribution of each size fraction after comminution and classification of PCBs samples. As can be seen, most of the material was concentrated in the coarser fraction $(+5 \mathrm{~mm})$, whereas the thin sheets containing aluminum comprised less than $4 \%$ 
in weight. The $\mathrm{Al}$ content in these sheets was determined by dissolving three aliquots of $1 \mathrm{~g}$ in $50 \mathrm{~mL}$ of $\mathrm{HCl} 1 \mathrm{M}$ at $60^{\circ} \mathrm{C}$ for $30 \mathrm{~min}$, followed by paper filtering to separate the non-dissolved fraction from the solution. After washing, drying, and weighing, the amount of $\mathrm{Al}$ dissolved was calculated. The sample presented an average aluminum content of $16.6 \%( \pm 0.6 \%)$.

Table 1. Mass fractions obtained after comminution and classification of PCBs.

\begin{tabular}{ccc}
\hline Size/Class & Mass $(\mathrm{g})$ & Mass $(\mathbf{\%})$ \\
\hline$+5 \mathrm{~mm}$ & 9428 & $55.7 \%$ \\
$-5+2 \mathrm{~mm}$ & 3760 & $22.2 \%$ \\
$-2 \mathrm{~mm}$ & 3078 & $18.2 \%$ \\
Thin Al sheets & 652 & $3.9 \%$ \\
$\Sigma$ & 16,918 & $100 \%$ \\
\hline
\end{tabular}

Figure 4 illustrates the elemental composition of the comminuted samples, showing that $\mathrm{Cu}, \mathrm{Al}, \mathrm{Fe}$, and $\mathrm{Sn}$ were the major metals presented in the wasted PCBs. The data also show considerable differences in metal content among the three particle size fractions. The intermediate size $(-5+2 \mathrm{~mm})$ presented the highest concentration values for most principal metals $(21.16 \%, 8.51 \%$, and $5.19 \%$ for $\mathrm{Cu}, \mathrm{Fe}$, and $\mathrm{Sn}$, respectively), also having significant contents of antimony $(3.18 \%)$ and lead $(2.72 \%)$. The coarser fraction $(+5 \mathrm{~mm})$ stands out for its higher aluminum content $(8.00 \%)$, whereas the finer size $(-2 \mathrm{~mm})$ presented appreciable contents of barium (1.65\%) and manganese $(1.40 \%)$. Significant contents of platinum group metals were not detected in any size, with silver being the only precious metal occurring in non-negligible amounts (179 ppm, $63 \mathrm{ppm}$, and $141 \mathrm{ppm}$ for the $+5 \mathrm{~mm},-5+2 \mathrm{~mm}$, and $-2 \mathrm{~mm}$ sizes, respectively). Overall, the data indicate that a significant enrichment in some elements is obtained after classifying the samples into the three size ranges used.

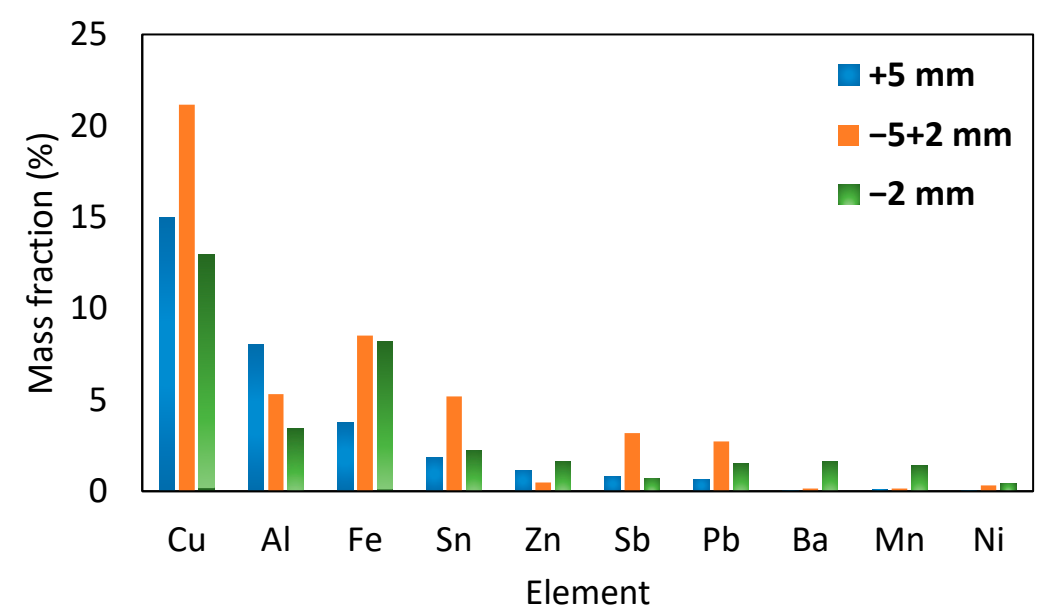

Figure 4. Content of the main metals present in the samples.

Figure 5 illustrates the results obtained in the sink and float essays in terms of accumulated float material in each separating density. In all cases, the amount of material below $0.8 \mathrm{~g} / \mathrm{cm}^{3}$ totaled less than $0.1 \%$ in mass, the reason being that this density range was not included in Figure 5. The size ranges $-5+2 \mathrm{~mm}$ and $-2 \mathrm{~mm}$ displayed similar density distribution profiles, which included about half the total mass below $2.1 \mathrm{~g} / \mathrm{cm}^{3}$ and a high concentration of material $(46.58 \%$ and $42.97 \%$ in mass, respectively) in the densest range $\left(+2.8 \mathrm{~g} / \mathrm{cm}^{3}\right)$. A higher concentration of metals is expected to occur in this high-density range, as confirmed by the distribution patterns of the major metals found in the samples, except for aluminum. Aluminum concentrated massively in the range of $-2.8+2.1 \mathrm{~g} / \mathrm{cm}^{3}$, especially in the $+5 \mathrm{~mm}$ size class, which presented about $68 \%$ of the total $\mathrm{Al}$ in this range. The nominal density of $\mathrm{Al}\left(2.7 \mathrm{~g} / \mathrm{cm}^{3}\right)$ certainly plays a role in it, although a significant concentration of $\mathrm{Al}$ also occurred in lower-densities ranges. The 
latter may be partially related to the fact that a considerable fraction of $\mathrm{Al}$ is contained in oil-filled electrolytic capacitors, whose oil can facilitate the adhesion of air bubbles, and thus, causing a reduction in apparent density during the sink and floats tests. On the other hand, the size range $-5+2 \mathrm{~mm}$ showed a remarkable concentration of $\mathrm{Cu}, \mathrm{Fe}$, and $\mathrm{Sn}$ above $2.8 \mathrm{~g} / \mathrm{cm}^{3}$, with an average of only $8.01 \%( \pm 4.10 \%)$ in mass of these metals below this density. In sum, the results show that at least three distinct concentrated products could be obtained after separation by density: (a) a light fraction $\left(-2.1 \mathrm{~g} / \mathrm{cm}^{3}\right)$, rich in polymeric material with low metal content; (b) a heavy fraction $\left(+2.8 \mathrm{~g} / \mathrm{cm}^{3}\right)$ enriched with metals, especially $\mathrm{Cu}, \mathrm{Fe}$, and $\mathrm{Sn}$; (c) an intermediate fraction $\left(-2.8+2.1 \mathrm{~g} / \mathrm{cm}^{3}\right)$ concentrating most of the aluminum.
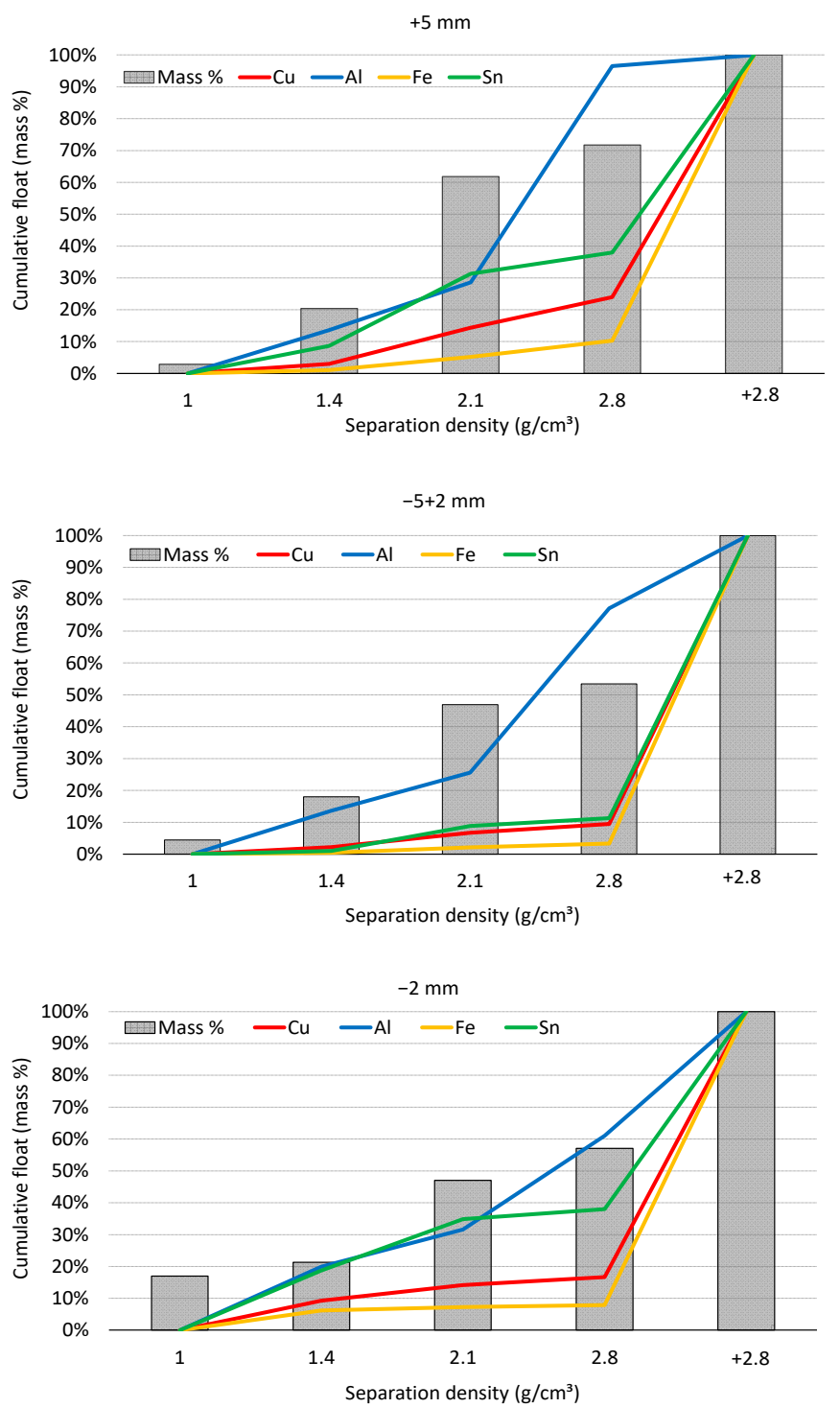

Figure 5. Density distribution curves for the different size ranges analyzed.

A visual inspection of the analyzed samples (Figure 6) revealed some relevant characteristics that help to delineate suitable strategies for separation routes. After comminution and classification, all samples showed a majority presence of lamellar-shaped pieces consisting of fragments of resins and polymeric substrate. Occurrences of aluminum bodies and $\mathrm{Pb}$-Sn solder alloys (isolated or adhered to the substrate) were also noticeable, together with copper wires. Copper wires tended not to be scattered but assembled in "chunks" of entangled wires. If appropriately controlled, this "entanglement tendency" could be explored for use in separating copper wires. 

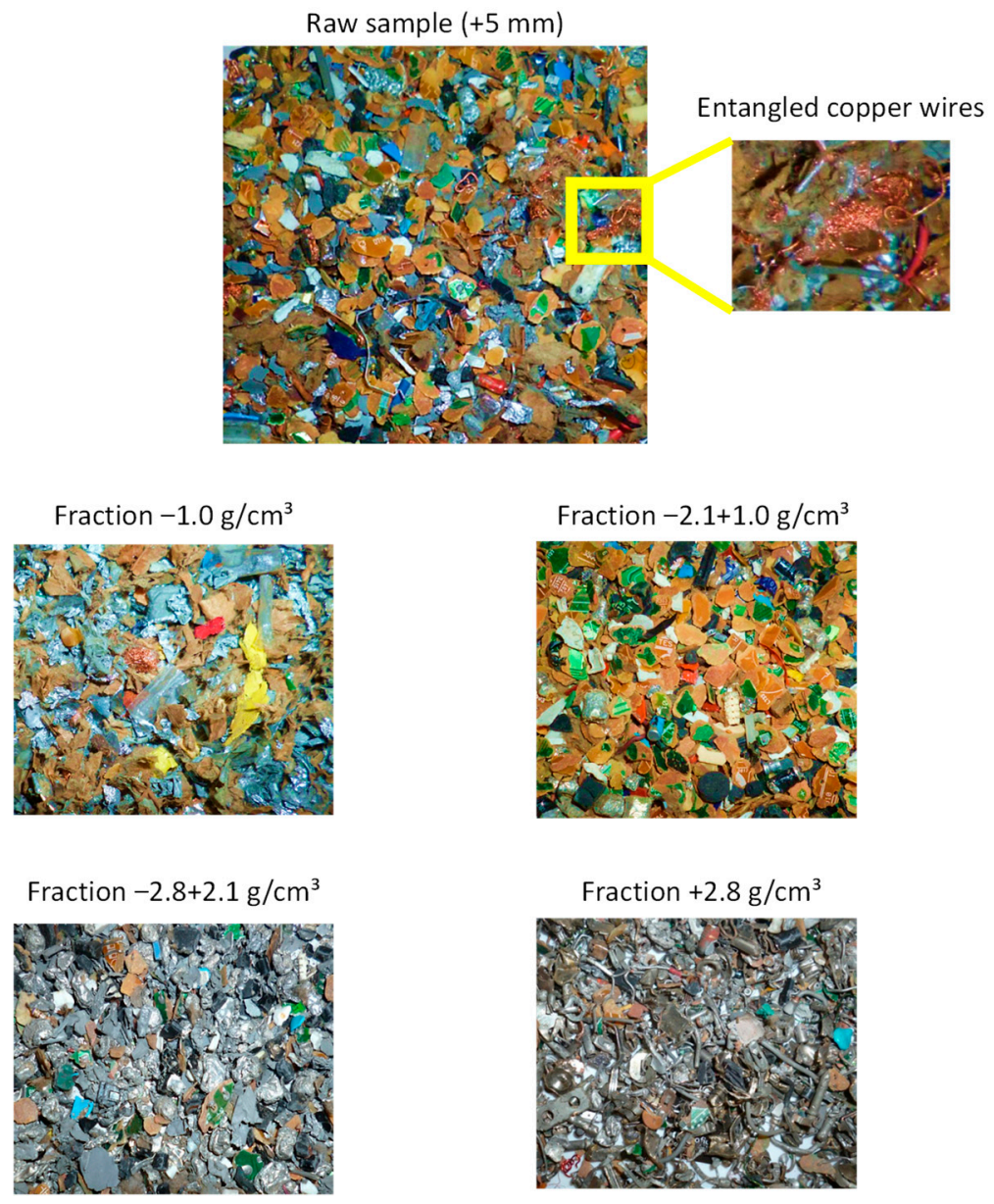

Figure 6. Observable visual characteristics of the $+5 \mathrm{~mm}$ sample before and after separation in different density ranges.

The material in the lower density range $\left(-1 \mathrm{~g} / \mathrm{cm}^{3}\right)$ showed the predominance of fibers and $\mathrm{Al}$ sheets. The existence of some loose copper wires was also noticeable. The occurrence of these higher-density materials in this fraction may be associated with the adherence to lower density material or even due to the adherence of air bubbles, as previously mentioned. The material in the density fractions $-1.4+1 \mathrm{~g} / \mathrm{cm}^{3}$ and $-2.1+1.4 \mathrm{~g} / \mathrm{cm}^{3}$ consisted predominantly of residues from the PCBs polymeric substrate, mostly free of metallic inclusions, either from solder alloy or copper traces. Within the range $-2.8+2.1 \mathrm{~g} / \mathrm{cm}^{3}$, the presence of aluminum is noted as parts or whole capacitor bodies (especially for $+5 \mathrm{~mm}$ ), or in the form of small laminates, widely spread throughout the sample. Finally, the heavy fraction $\left(+2.8 \mathrm{~g} / \mathrm{cm}^{3}\right)$ consisted basically of component terminals (mostly tinned), copper and brass contactors with or without nickel galvanic protective layer, as well as copper wires, resistor terminals, metal clips, springs, screws, and other undefined ferrous objects. Considering that most metals concentrated in this density range, an additional analysis of the different components compounding this fraction was carried out in order to delineate suitable operations for further enrichment of metals in this fraction.

\subsection{Composition Analysis of $+2.8 \mathrm{~g} / \mathrm{cm}^{3}$ Fraction}

The results previously described indicated that most metals in old, wasted PCBs concentrated in densities range above $2.8 \mathrm{~g} / \mathrm{cm}^{3}$. Thus, extra analysis was carried out to determine the distribution of metals over individual classes of materials within the $+2.8 \mathrm{~g} / \mathrm{cm}^{3}$ sample. For this purpose, the sizes $+5 \mathrm{~mm}$ and $-5+2 \mathrm{~mm}$ were separated into four distinct material types: (a) copper wires; (b) magnetic components; (c) non-magnetic metallic components; (d) other non-metallic materials, denominated as "residues". The magnetic fraction was 
separated by successive passages of a block of neodymium magnet over the spread samples, whereas the other three fractions were carefully separated by hand. Due to the small size of the $-2 \mathrm{~mm}$ class, separation by hand was not feasible, so that, in this case, only a magnetic and a non-magnetic fraction were segregated. All subsamples thus generated were weighed and chemically analyzed using the procedures described in Section 2.3.

Table 2 shows the mass distribution of the different categories in each size range. It is worth noting that the higher content of non-magnetic material in the $-2 \mathrm{~mm}$ size can be partially due to the concentration of copper wires and the so-called "others" fraction in the non-magnetic class. The proportion of magnetic material significantly increased for smaller sizes, which is possibly related to a greater liberation degree of ferrous pieces during fragmentation. On the other hand, a larger amount of copper wires was presented in the coarser size $(+5 \mathrm{~mm})$ than in the $-5+2 \mathrm{~mm}$ size, apparently contradicting the initial characterization (see Figure 4). However, a considerable amount of copper in the latter was associated with the non-magnetic fraction, as discussed below.

Table 2. Distribution of different material classes in the $+2.8 \mathrm{~g} / \mathrm{cm}^{3}$ range.

\begin{tabular}{ccccc}
\hline \multirow{2}{*}{ Size/Class } & \multicolumn{4}{c}{ Material Class (Mass\%) } \\
\cline { 2 - 5 } & Copper Wires & Magnetics & Non-Magnetics & Residues \\
\hline$+5 \mathrm{~mm}$ & $22.50 \%$ & $37.90 \%$ & $29.50 \%$ & $10.10 \%$ \\
$-5+2 \mathrm{~mm}$ & $9.60 \%$ & $40.30 \%$ & $22.70 \%$ & $27.40 \%$ \\
$-2 \mathrm{~mm}$ & - & $45.70 \%$ & $54.30 \%$ & - \\
\hline
\end{tabular}

Figure 7 illustrates the elemental composition and the visual aspect of the copper wires. Entrained fibrous material residues that originated during comminution acted as "nets", contributing to the formation of clusters of wires. This phenomenon occurred especially for the $+5 \mathrm{~mm}$ size, as can be seen in Figure $7 \mathrm{a}$, and suggests that the presence of fibrous materials could enhance the entanglement tendency of copper wires previously discussed. This indicates that a high purity copper concentrate could be obtained by the selective recovery of the copper wires.

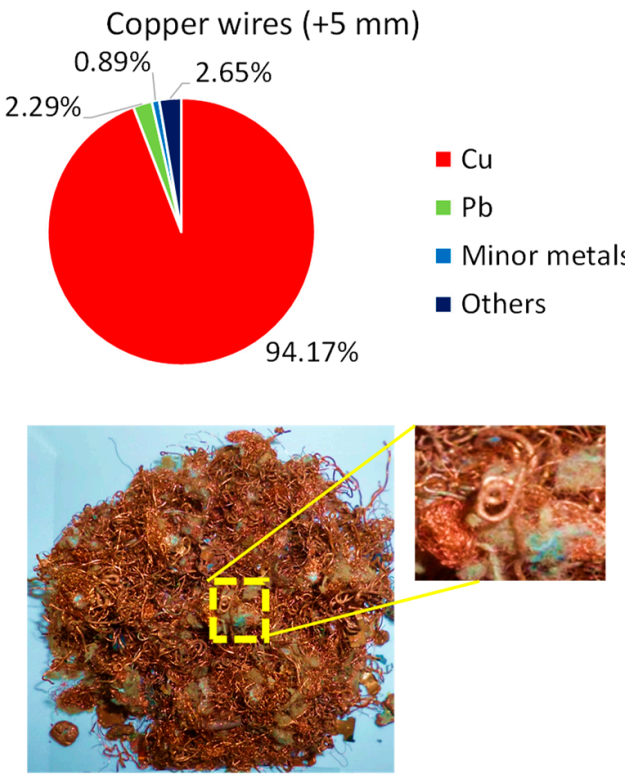

(a)
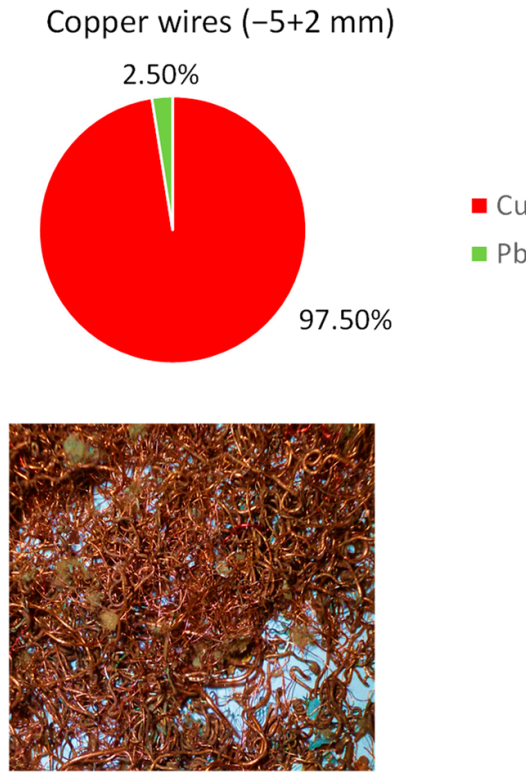

(b)

Figure 7. Elemental composition and pictures of copper wires separated in the $+2.8 \mathrm{~g} / \mathrm{cm}^{3}$ fraction. (a) $+5 \mathrm{~mm}$; (b) $-5+2 \mathrm{~mm}$. "Minor metals" consider the sum of the elements $\mathrm{Cu}, \mathrm{Al}, \mathrm{Fe}, \mathrm{Sn}, \mathrm{Zn}$, $\mathrm{Pb}, \mathrm{Ba}, \mathrm{Mn}$, and Ni when not individually displayed. "Others" consider the sum of non-metallic elements and trace metals. 
The composition of the magnetic class in each size range is shown in Figure 8. Larger ferrous parts were concentrated in the $+5 \mathrm{~mm}$ size, possibly due to their higher mechanical strength and more difficult comminution. Screws, metal clips, springs, and other undefined ferrous objects can be seen. A significant number of resistor terminals could be observed in the $-5+2 \mathrm{~mm}$ size. The magnetic properties of these terminals reinforce the hypothesis that they are partially constituted of iron wire with a tin final finish, as there is a significant amount of $\mathrm{Sn}-\mathrm{Pb}$ solder dots adhered to the terminals. On the other hand, the magnetic fraction at $-2 \mathrm{~mm}$ showed the majority presence of fragmented transformer core pieces consisting of ferrite ceramics. It is reasonable to suppose that the fragility of this ceramic material leads to a more pronounced size reduction compared to other PCB constituents. The concentration of ferrite in the smallest size suggests the possibility of recycling this material if a suitable treatment for removing impurities is applied.
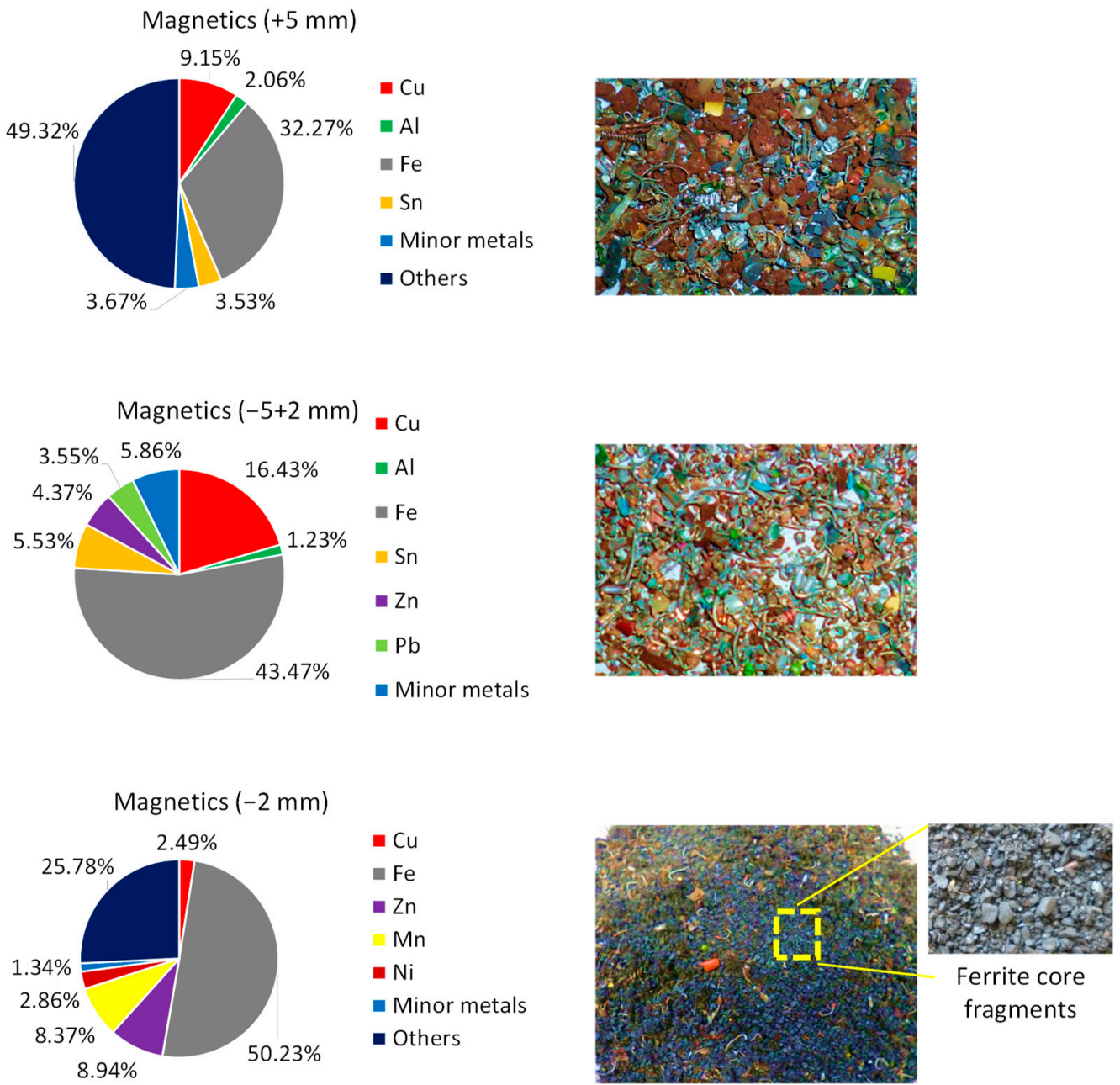

Figure 8. Elemental composition and pictures of the magnetic portion separated in the $+2.8 \mathrm{~g} / \mathrm{cm}^{3}$ fraction. "Minor metals" consider the sum of the elements $\mathrm{Cu}, \mathrm{Al}, \mathrm{Fe}, \mathrm{Sn}, \mathrm{Zn}, \mathrm{Pb}, \mathrm{Ba}, \mathrm{Mn}$, and Ni when not individually displayed. "Others" consider the sum of non-metallic elements and trace metals.

The elemental composition of the magnetic fraction varied significantly according to the particle size, also showing appreciable contents of non-ferrous metals despite the majority presence of iron. Much of these metals came from the electrolytic plating used to cover capacitors and resistors pieces made of iron so that they were carried together with the magnetic material stream. Indeed, previous work already addressed the possibility of recovering tin from iron terminals in electronic wastes [32].

Regarding the concentration of metals only, better results were observed in the $-5+2 \mathrm{~mm}$ size range, since the presence of non-metals ("others" class in Figure 8) was virtually null. It 
also presented considerable amounts of $\mathrm{Cu}, \mathrm{Sn}, \mathrm{Zn}$, and $\mathrm{Pb}$. Differently, the $+5 \mathrm{~mm}$ size had about half of its mass composed of non-metals and displayed small quantities of aluminum $(\approx 2 \%)$. The $-2 \mathrm{~mm}$ size stands out from the others for having significant quantities of $\mathrm{Zn}$, $\mathrm{Mn}$, and Ni. The presence of Ni could be attributed to the presence of nickel electroplating, whereas some ferrites have notable amounts of zinc in their composition (zinc ferrites) [33].

Figure 9 shows the composition and visual aspects of materials in the non-magnetic portion. This fraction was expected to be the most valuable since it concentrates many nonferrous metals presented in the wasted PCBs. As can be seen, the elemental composition confirms it since the number of non-ferrous metals like $\mathrm{Cu}, \mathrm{Sn}, \mathrm{Pb}$, and $\mathrm{Zn}$ comprised the largest portion in all size ranges, although the distribution of metals over different sizes significantly varied. The $+5 \mathrm{~mm}$ size showed a large presence of unwanted non-metallic materials (34.23\% in mass), which probably occurred due to the incomplete liberation of metallic pieces from the polymeric substrate in this size range, as highlighted in Figure 9. On the other hand, the size $-5+2 \mathrm{~mm}$ was composed of practically only non-ferrous metals, showing a high concentration of $\mathrm{Cu}(+70 \%)$ and considerable amounts of $\mathrm{Sn}, \mathrm{Pb}$, and $\mathrm{Zn}$. Unlike the coarser size, the material in this fraction mainly consisted of terminals, clips, and rods finish coated (most possibly with zinc), not adhered to the polymeric substrate. Finally, as the coarser material, non-metallic material comprised a substantial portion of the $-2 \mathrm{~mm}$ size fraction. In this case, however, its occurrence was not related to incomplete liberation but with the great tendency of entanglement of the small copper wires with fibrous materials from the boards' resin. This resulted in the formation of large chunks of mixed entangled material (such as steel wool), retaining light and dense pieces (including those having $\mathrm{Al}$, found only in this size) in one single cluster, such as the one displayed in Figure 9.
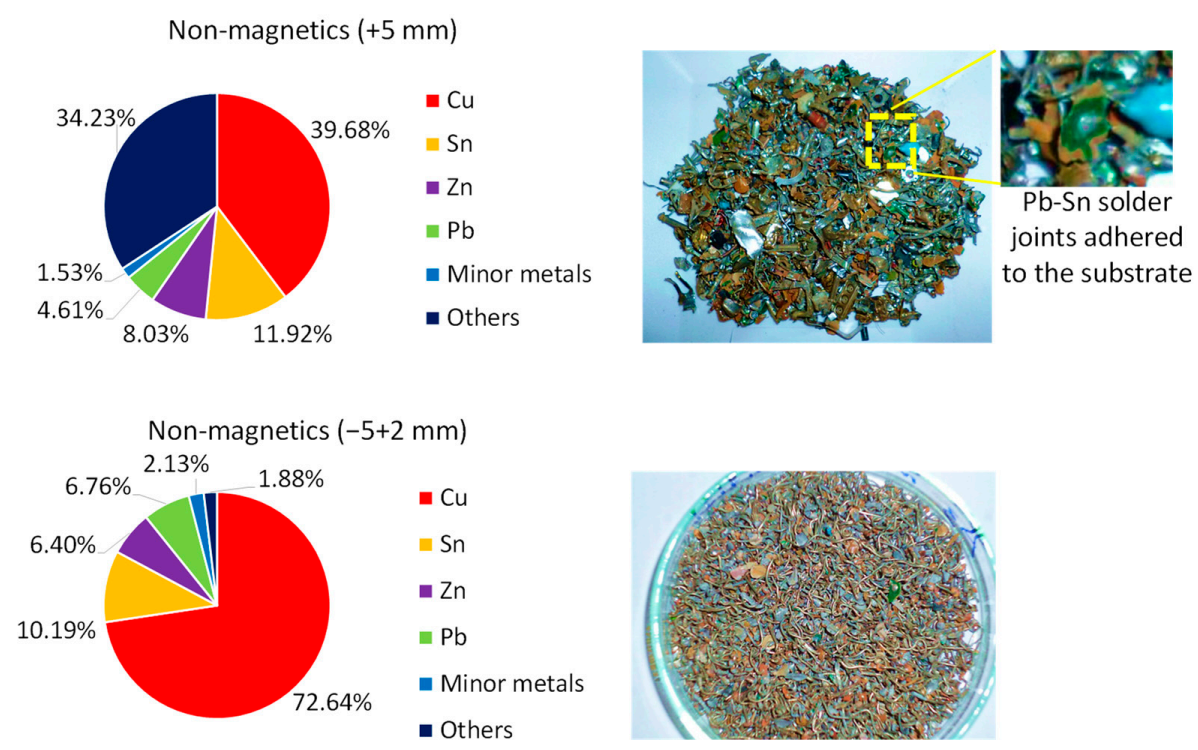

Non-magnetics (-2 mm)
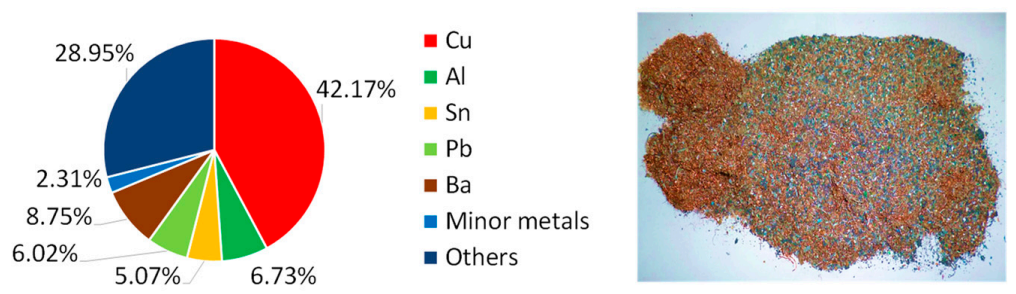

Figure 9. Elemental composition and pictures of the non-magnetic portion separated in the $+2.8 \mathrm{~g} / \mathrm{cm}^{3}$ fraction. "Minor metals" consider the sum of the elements $\mathrm{Cu}, \mathrm{Al}, \mathrm{Fe}, \mathrm{Sn}, \mathrm{Zn}, \mathrm{Pb}, \mathrm{Ba}, \mathrm{Mn}$, and $\mathrm{Ni}$ when not individually displayed. "Others" consider the sum of non-metallic elements and trace metals. 
The smaller size fraction also showed an unexpected high content of barium (almost $9 \%$ in mass). Although it has received minor attention within the context of e-wastes, it is known that barium was used in old TV vacuum tubes for removing unwanted gases and to improve the creep resistance of $\mathrm{Pb}-\mathrm{Sn}$ soldering alloys [34]. As a toxic compound [35], its high concentration indicates the need of removing it from this non-magnetic fraction before further recycling. Overall, the results obtained for the non-magnetic fraction point out the likelihood that significant liberation of non-ferrous metals from the substrate of old wasted PCBs can be achieved for comminution below $5 \mathrm{~mm}$. Conversely, entanglement effects can hamper the concentration of metals if the material is too fine (below $2 \mathrm{~mm}$ ), thus placing the $-5+2 \mathrm{~mm}$ size range as an optimal grading for concentration of non-ferrous metals.

The characteristics of the residue's constituents are shown in Figure 10. This category comprised mainly identifiable non-metallic material that was hand sorted from the nonmagnetic fractions. It represented about $10 \%$ in mass of the $+2.8 \mathrm{~g} / \mathrm{cm}^{3}$ sample for the $+5 \mathrm{~mm}$ size, exhibiting appreciable amounts of copper contained in coated wires. These, together with fragments of graphite insulators, constituted the bulk of this class. They were carefully separated by hand and analyzed according to the same procedure described in Section 2.3 (Figure 10a). Conversely, the residues class encompassed more than a quarter of the $+2.8 \mathrm{~g} / \mathrm{cm}^{3}$ sample for the $-5+2 \mathrm{~mm}$ size and showed a massive concentration of metals (resembling, in terms of distribution, the non-magnetic fraction of the $+5 \mathrm{~mm}$ size). This can be attributed to the occurrence of chunks of entangled materials quite like those displayed by the non-magnetic class, $-2 \mathrm{~mm}$ size (Figure 10b). These chunks embodied almost $90 \%$ of the mass of the residues in this size range and their constituents were in general too fine for hand sorting. This reinforces the evidence that portions of comminuted PCBs rich in copper wires or polymeric fibers tend to cluster together, forming a "net" that holds fragments of different compositions. Additionally, it indicated that, although it allows obtaining more richer concentrates in other categories (i.e., copper wires, magnetic, and non-magnetic), the size range $-5+2 \mathrm{~mm}$ can entail a larger loss of metals in the residues.

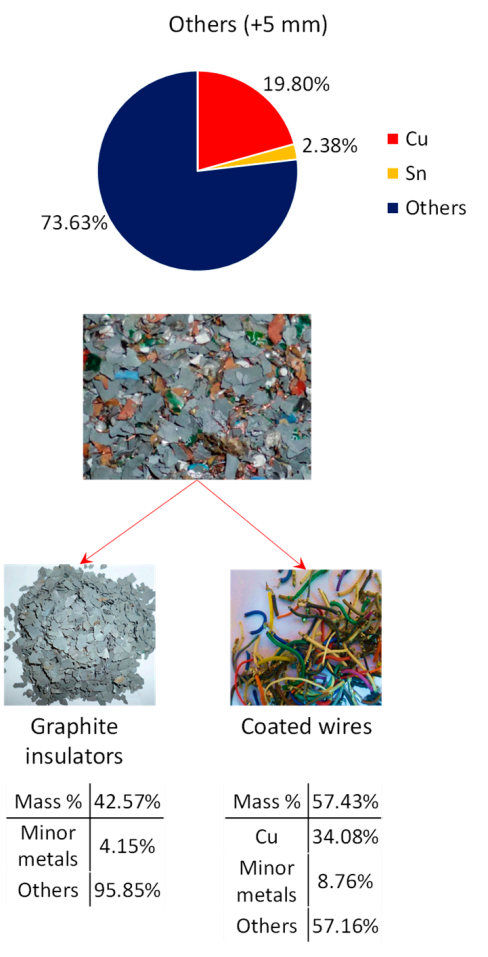

(a)

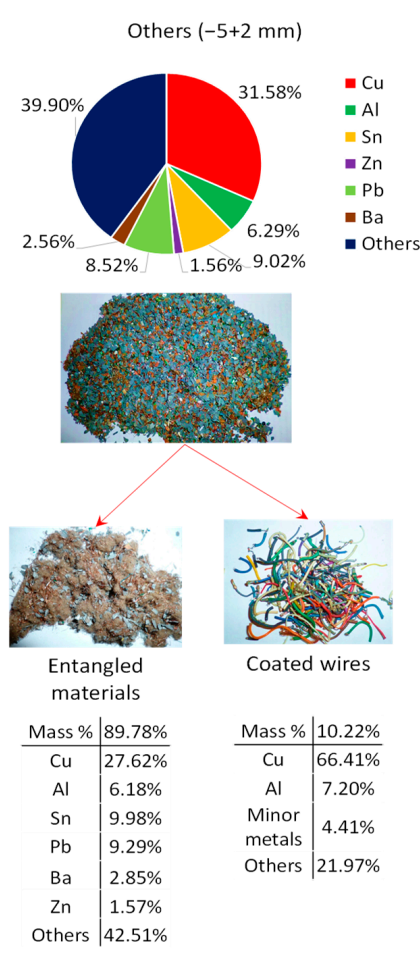

(b)

Figure 10. Elemental composition and pictures of residues separated in the $+2.8 \mathrm{~g} / \mathrm{cm}^{3}$ fraction. (a) $+5 \mathrm{~mm}$; (b) $-5+2 \mathrm{~mm}$. "Minor metals" consider the sum of the elements $\mathrm{Cu}, \mathrm{Al}, \mathrm{Fe}, \mathrm{Sn}, \mathrm{Zn}, \mathrm{Pb}, \mathrm{Ba}, \mathrm{Mn}$, and Ni when not individually displayed. "Others" consider the sum of non-metallic elements and trace metals. 


\subsection{Induced Entanglement of Copper Wires}

As discussed previously, the tendency of entanglement displayed by copper wires and polymeric fibers was detrimental for the separation, locking pieces of different compositions together in the same cluster. However, one could harness this phenomenon for a selective concentration of copper if appropriately induced. Seeking to test this hypothesis, an experimental apparatus was established to test the entanglement effect, consisting of a rotary drum of $20 \mathrm{~cm}$ in diameter and $30 \mathrm{~cm}$ in length mounted on trunnion wheels and rotating at 40 RPM (Figure 11a). A similar apparatus has recently been tested with the same purpose by Phengsaart et al. [20]. The tests consisted of sealing the drum with $400 \mathrm{~g}$ of unseparated samples of size $+5 \mathrm{~mm}$ under rotation for 15 and $30 \mathrm{~min}$. The samples $-5+2 \mathrm{~mm}$ and $-2 \mathrm{~mm}$ were not tested due to the lack of representative material after carrying out the characterization described in the previous section. The tests were conducted based on the assumption that the granular motion caused by the drum rotation would increase the contact either among copper wires and between copper wires and fibers, forming large entangles that could be separated by sieving or even by hand. The agitation of the material could also aid in the disaggregation of pieces that may eventually get stuck to the wires.

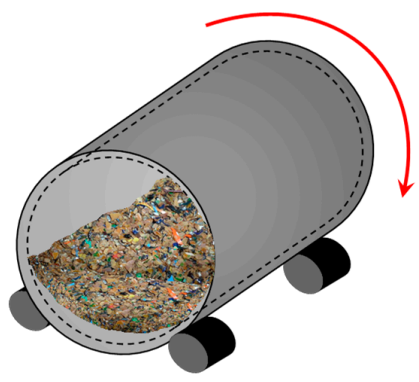

(a)

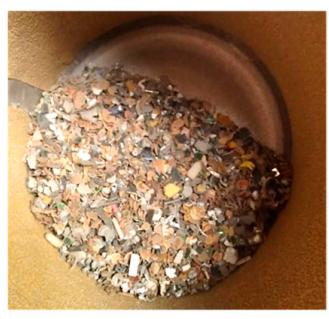

(b)

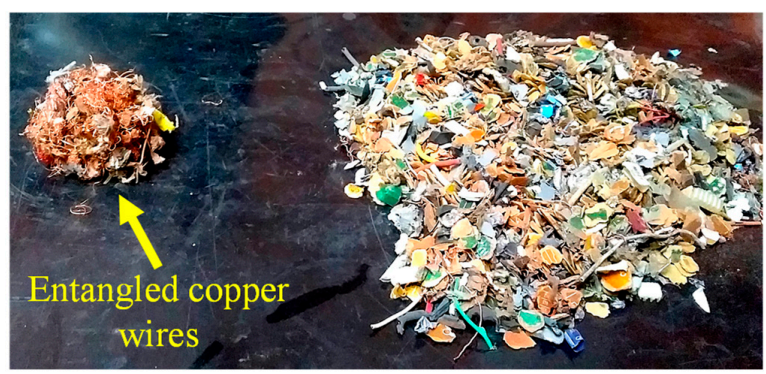

(c)

Figure 11. Tests of selective recovery of copper wires by entanglement. (a) Concept illustration. (b) Samples of comminuted PCBs inside the drum before testing. (c) Test outcome for the $+5 \mathrm{~mm}$ sample, highlighting the formation of a chunk of entangled copper wires.

Tests results showed that the drumming process favored the formation of large entangles of copper wires (Figure 11c). In general, after drumming, a single chunk of about $40 \mathrm{~mm}$ of tangled wires was produced, amounting to less than $1 \%$ in mass of the drum charge (Table 3). The content of copper in the clusters from different essays, analyzed according to the procedures described in Section 2.3, were similar and averaged $95.20 \%$ $( \pm 3.06 \%)$ in mass, being the balance composed mainly of polymeric material (fibers). The proportion of copper recovered in the tangles was around 5\% (Table 3), and the effect of drumming time barely affected it. It is reasonable to suppose that vigorous shaking of the particles did not occur due to the smooth surface of the drum and to the low rotation frequencies used so that the contact between wires was suboptimal. Future tests should evaluate the influence of varied drum surface roughness and rotation speed conditions on the entanglement effect. Notwithstanding, these preliminary results suggest that the 
trend of entanglement of copper wires can be explored in benefit of their separation if the entanglement effect is suitably induced.

Table 3. Drumming tests results in terms of yield and recovery of copper tangles.

\begin{tabular}{ccccc}
\hline \multirow{2}{*}{ Mass \% } & \multicolumn{5}{c}{ Drumming Time (min) } \\
\cline { 2 - 5 } & & $\mathbf{1 5}$ & & 30 \\
\cline { 2 - 5 } & Test 1 & Test 2 & Test 1 & Test 2 \\
\hline Yield & $0.80 \%$ & $0.74 \%$ & $0.89 \%$ & $0.97 \%$ \\
Cu recovery & $5.08 \%$ & $4.69 \%$ & $5.65 \%$ & $6.15 \%$ \\
\hline
\end{tabular}

\section{Discussion}

\section{Processing Route}

The characterization results described in the previous section indicate that a reasonable separation of constituents of old wasted PCBs could be achieved using a combination of size, density, and magnetic-based separation methods. On this basis, a processing route was envisaged for the size ranges studied together with their respective material balances, as exhibited in Figure 12. The treatment strategy involves two stages of density separation (cut density of $2.1 \mathrm{~g} / \mathrm{cm}^{3}$ in the first stage and $2.8 \mathrm{~g} / \mathrm{cm}^{3}$ in the second stage) followed by magnetic separation of the denser fraction. After processing, four product streams are obtained: (1) a non-metallic fraction, concentrating most of the organic material (polymers) present in the PCBs; (2) an aluminum-rich concentrate, a magnetic fraction, enriched with iron, and a dense, non-magnetic fraction, rich in non-ferrous metals, especially copper. Table 4 shows the content of the main metals in each concentrate stream.

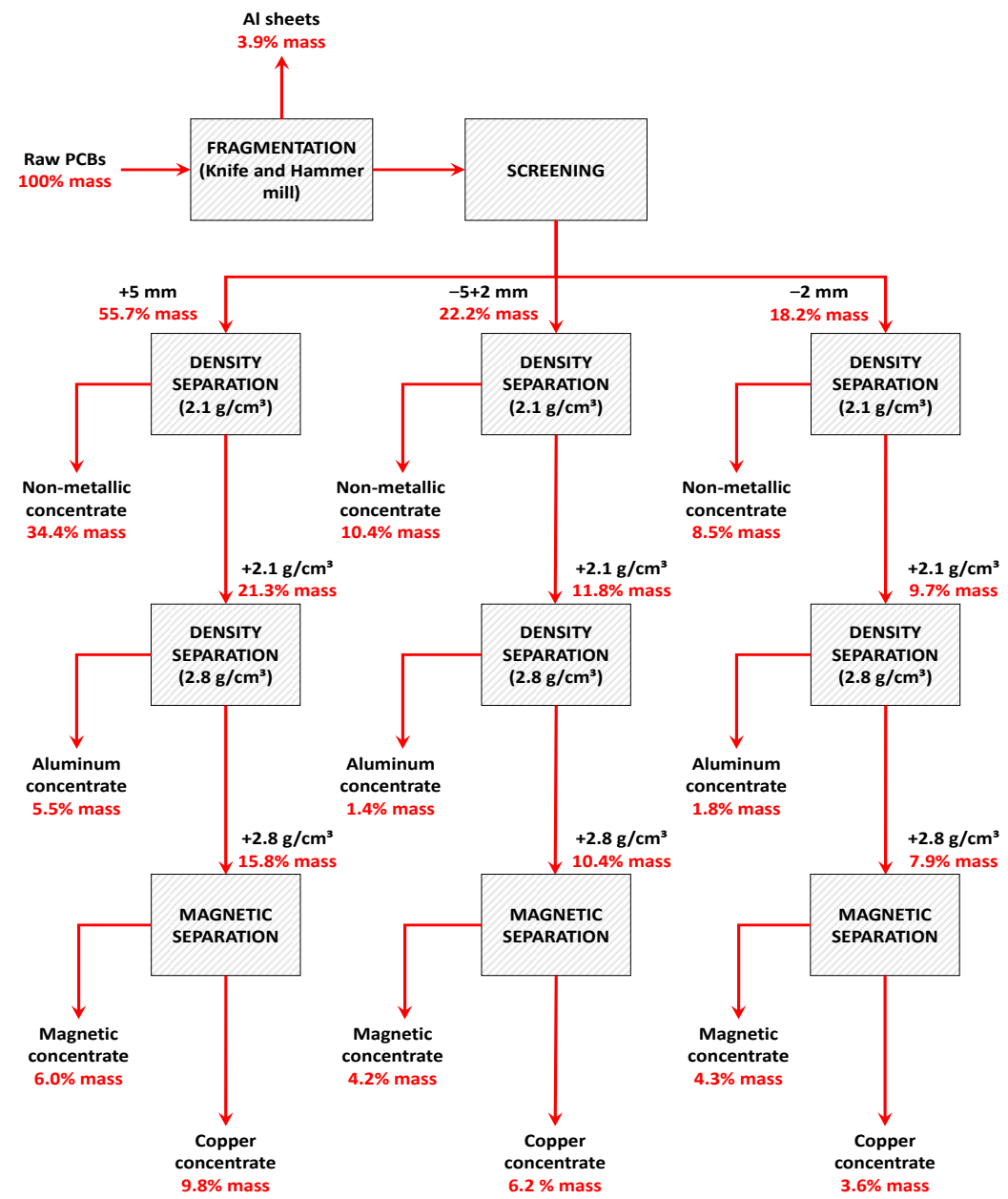

Figure 12. Proposed processing route of old PCBs and the global material balance. 
Table 4. Content (mass\%) of the main metals in the feed and the concentrate streams. The Bal (balance) class includes minor metals (concentration below 1\%), trace metals, and non-metallic elements.

\begin{tabular}{|c|c|c|c|c|c|c|c|}
\hline \multicolumn{8}{|c|}{$+5 \mathrm{~mm}$} \\
\hline Stream & $\mathrm{Cu}$ & Al & $\mathrm{Fe}$ & Sn & Zn & $\mathrm{Pb}$ & Bal \\
\hline Feed & 15.00 & 8.00 & 3.77 & 1.86 & 1.14 & 0.63 & 69.60 \\
\hline Non-metallic & 3.49 & 3.71 & 0.32 & 0.94 & 0.00 & 0.00 & 91.54 \\
\hline Aluminum & 14.47 & 54.72 & 1.91 & 1.26 & 1.01 & 0.91 & 25.72 \\
\hline Magnetic & 9.15 & 2.06 & 32.27 & 3.53 & 0.92 & 0.85 & 51.22 \\
\hline Copper & 59.39 & 0.32 & 0.00 & 4.41 & 5.35 & 2.53 & 28.00 \\
\hline \multicolumn{8}{|c|}{$-5+2 \mathrm{~mm}$} \\
\hline Stream & $\mathrm{Cu}$ & $\mathrm{Al}$ & $\mathrm{Fe}$ & Sn & $\mathrm{Zn}$ & $\mathrm{Pb}$ & Bal \\
\hline Feed & 21.16 & 5.31 & 8.51 & 5.19 & 0.48 & 2.72 & 56.64 \\
\hline Non-metallic & 3.05 & 2.90 & 0.46 & 0.99 & 0.02 & 0.11 & 92.47 \\
\hline Aluminum & 9.05 & 42.08 & 1.52 & 2.02 & 0.16 & 1.44 & 43.72 \\
\hline Magnetic & 16.43 & 1.23 & 43.47 & 5.53 & 2.45 & 3.55 & 27.36 \\
\hline Copper & 57.75 & 3.54 & 0.13 & 12.77 & 0.00 & 6.85 & 18.97 \\
\hline \multicolumn{8}{|c|}{$-2 \mathrm{~mm}$} \\
\hline Stream & $\mathrm{Cu}$ & $\mathrm{Al}$ & $\mathrm{Fe}$ & Sn & $\mathrm{Zn}$ & $\mathrm{Pb}$ & Bal \\
\hline Feed & 12.96 & 3.42 & 8.18 & 2.24 & 1.62 & 1.49 & 70.10 \\
\hline Non-metallic & 3.87 & 2.27 & 1.26 & 1.63 & 0.28 & 0.35 & 90.34 \\
\hline Aluminum & 3.29 & 9.87 & 0.58 & 0.70 & 0.14 & 0.19 & 85.23 \\
\hline Magnetic & 2.58 & 0.44 & 31.88 & 0.00 & 5.57 & 0.30 & 59.22 \\
\hline Copper & 51.97 & 6.43 & 0.44 & 7.12 & 0.91 & 6.29 & 26.83 \\
\hline
\end{tabular}

As can be seen, the first density separation stage can remove about half of the mass of crushed PCBs in all size ranges (slightly more than the half for the $+5 \mathrm{~mm}$ size) as a light fraction. Although its metal content is not negligible, about $90 \%$ of its mass is composed of non-metallic materials, the vast majority being organic substrates (resins, polymers, fiberglass, etc.). These waste plastics are an intermediate product on their own, as they can be further processed to recover individual polymers $[36,37]$ or, due to their high carbon content, used as a combustible or a reducing agent in smelting processes [38]. The denser stream feeds the second density separation stage, generating a concentrate in the density range $-2.8+2.1 \mathrm{~g} / \mathrm{cm}^{3}$ that is rich in aluminum, except for the $-2 \mathrm{~mm}$ size, whose composition is more like that of the non-metallic product obtained in the first separation stage. Aluminum is known for its amenability to being selectively recovered in eddy current separators due to its high conductivity and low density (e.g., compared to copper, which is significantly denser) [39]. Although not addressed in this study, the upgrade of this $\mathrm{Al}$ concentrate through eddy current separation could produce a high purity product, which in turn could be supplied to scrap remelters. The $+2.8 \mathrm{~g} / \mathrm{cm}^{3}$ product feeds a magnetic separation stage, resulting in a magnetic concentrated enriched with iron and a non-magnetic product rich in copper $(+50 \%$ in mass in all cases) and other minor non-ferrous metals, such as $\mathrm{Sn}$ and $\mathrm{Pb}$.

Table 5 exhibits the separation indexes related to the concentration of the main metals presented in the analyzed PCBs. The enrichment factor (concentrate content divided by initial content) has varied according to element and particle size, being comparatively high for $\mathrm{Al}$ and $\mathrm{Fe}$ in the coarser size ranges. Copper, on the other hand, has experienced a better enrichment in the $-2 \mathrm{~mm}$ size than in the intermediate size range. When analyzed altogether, the other metals ( $\mathrm{Sn}, \mathrm{Zn}$, and $\mathrm{Pb}$ ) have not displayed a defined pattern of preferential concentration. Regardless of the size, yield values higher than $90 \%$ and $80 \%$ have been reached for $\mathrm{Fe}$ and $\mathrm{Zn}$, respectively, followed by $\mathrm{Pb}(+70 \%)$ and $\mathrm{Cu}(69-79 \%)$. $\mathrm{Al}$ and $\mathrm{Sn}$ yields have been more influenced by the particle size, the first being poorly recovered in the $-2 \mathrm{~mm}$ size.

As mentioned earlier, silver was the only precious metal present in significant amounts in the PCBs. In the $+5 \mathrm{~mm}$ size, its content in the non-magnetic product was 3.25 times higher than in the raw feed (583 ppm versus 179 ppm). Conversely, Ag was not detected for 
the $+2.8 \mathrm{~g} / \mathrm{cm}^{3}$ concentrates of the other sizes, in these cases only found in the $-2.1 \mathrm{~g} / \mathrm{cm}^{3}$ with contents of $131 \mathrm{ppm}$ and $265 \mathrm{ppm}$ for $-5+2 \mathrm{~mm}$ and $-2 \mathrm{~mm}$ sizes, respectively.

Table 5. Evaluation indexes of the separation of main metals contained in the wasted PCBs.

\begin{tabular}{ccccccc}
\hline & \multicolumn{5}{c}{ Index/Size Range } \\
\cline { 2 - 7 } Element & $\mathbf{5} \mathbf{~ m m}$ & $\begin{array}{c}\text { Enrichment } \\
-\mathbf{5}+\mathbf{2} \mathbf{~ m m}\end{array}$ & $\mathbf{- 2} \mathbf{~ m m}$ & $\mathbf{+ 5} \mathbf{~ m m}$ & $\mathbf{- 5 + 2} \mathbf{~} \mathbf{m}$ & $\mathbf{- 2} \mathbf{~ m m}$ \\
\hline $\mathrm{Cu}$ & 3.96 & 2.73 & 4.01 & $69.51 \%$ & $75.89 \%$ & $78.75 \%$ \\
$\mathrm{Al}$ & 6.84 & 7.92 & 2.89 & $67.90 \%$ & $51.53 \%$ & $28.83 \%$ \\
$\mathrm{Fe}$ & 8.56 & 5.11 & 3.90 & $91.71 \%$ & $95.86 \%$ & $90.95 \%$ \\
$\mathrm{Sn}$ & 2.37 & 2.46 & 3.19 & $41.64 \%$ & $68.47 \%$ & $62.55 \%$ \\
$\mathrm{Zn}$ & 4.70 & 5.12 & 3.43 & $82.53 \%$ & $96.04 \%$ & $80.10 \%$ \\
$\mathrm{~Pb}$ & 4.04 & 2.52 & 4.23 & $70.99 \%$ & $70.17 \%$ & $83.08 \%$ \\
\hline
\end{tabular}

It is worth emphasizing that the results here obtained consider near-optimal separation conditions in each stage. The cut densities used $\left(2.1\right.$ and $\left.2.8 \mathrm{~g} / \mathrm{cm}^{3}\right)$ were adjusted using organic dense liquids (see Section 2.2), which are not suitable for use on a real scale due to their toxicity and corrosiveness. Real density separation devices, such as heavy media, jigs, and teetered bed separators, always have an imperfection associated with their difficulty to maintain a stable separation density, which must be considered when scaling up the process. The same occurs for screens and magnetic separation equipment.

Although the enrichment levels obtained are lower than those typically found in mineral processing operations, some concentrates generated by the proposed route have relatively advantageous characteristics compared to those from the primary extraction. Copper, for instance, is typically found in sulfide ores containing up to $2 \% \mathrm{Cu}$, which after milling and beneficiation through froth flotation, produces a concentrate containing $15-35 \% \mathrm{Cu}[40]$. This concentrate needs to undergo several complex operations, such as matte smelting, deoxidation, and electrowinning, to finally obtain copper for commercial use [41]. Here, the obtained results point out that a concentrate containing almost $60 \%$ in mass of metallic copper can be obtained without using expensive operations such as grinding and flotation.

\section{Conclusions}

Electronic wastes from old devices, such as TV boards and stereos, generally have fewer valuable metals when compared to new ones, so that its recycling has been little addressed in the literature. Nevertheless, these wastes represent a significant part of the electronic scrap generated in developing countries, being commonly sold by collectors as low-value material to recycling hubs abroad. Increasing the content of metals in this waste stream could be potentially beneficial for recyclers' income and, consequently, for the recycling market itself. On this basis, this study investigated the possibility of concentrating metals from old, wasted PCBs through a physical separation-based route.

It was found that a combination of fragmentation, size classification, density, and magnetic separation operations allow obtaining four distinct products: (a) a non-metallic fraction, basically composed of plastics and resins; (b) a product enriched with aluminum; (c) a magnetic material stream, containing mainly iron; (d) a final concentrate containing more than $50 \%$ in mass of copper and enriched with $\mathrm{Sn}$ and $\mathrm{Pb}$. A particular advantage of the proposed route is the possibility of selective recovery of aluminum, which is usually slagged in smelting processes and, thus, discarded or under-reused.

After fragmentation and classification of PCBs into three particle size fractions, it was verified that most of the material was situated in the $+5 \mathrm{~mm}$ coarser fraction $(55.73 \%)$, followed by the $-5+2 \mathrm{~mm}$ and $-2 \mathrm{~mm}$ particle size fractions $(22.22 \%$ and $18.19 \%$, respectively). $\mathrm{Cu}, \mathrm{Al}, \mathrm{Fe}$, and $\mathrm{Sn}$ constituted the major metals encountered in all particle sizes, including some peak concentrations of $\mathrm{Zn}, \mathrm{Sb}, \mathrm{Pb}, \mathrm{Ba}$, and $\mathrm{Mn}$ in specific size ranges.

Results obtained from the float-and-sink analysis showed that aluminum was mostly concentrated in the density range of $+2.1-2.8 \mathrm{~g} / \mathrm{cm}^{3}$, especially in the $+5 \mathrm{~mm}$ fraction (about $55 \%$ 
in mass of $\mathrm{Al}$ ), whereas the highest concentration of other metals occurred in the $+2.8 \mathrm{~g} / \mathrm{cm}^{3}$ density, the $-5+2 \mathrm{~mm}$ size having the greatest proportion of material in this range. After a detailed analysis of the composition of the densest fraction $\left(+2.8 \mathrm{~g} / \mathrm{cm}^{3}\right)$, a tendency for the formation of large individual tangles composed of copper and polymer fibers was observed. Although detrimental to the separation, preliminary tests have indicated the possibility of exploring this entanglement effect for selective recovery of copper through drumming. The analysis of the macro constitution, especially in larger sizes, also showed the possibility for recovery of other products such as ferrite and graphite insulators.

Future studies should include follow-up work to evaluate metals extractive routes from the obtained concentrates, the possibility of recovering specific materials (such as ferrite transformer cores), and whether the inclusion of other physical separation techniques (such as drumming and electrostatic separation) can upgrade the content of metals in concentrates.

Author Contributions: Conceptualization, P.J.W.K.d.B.; methodology, P.J.W.K.d.B. and W.M.A.; validation, I.A.S.d.B., R.M.C.T. and C.H.S.; formal analysis, P.J.W.K.d.B. and W.M.A.; investigation, P.J.W.K.d.B.; resources, R.M.C.T. and J.O.M.; data curation, P.J.W.K.d.B.; writing-original draft preparation, W.M.A.; writing-review and editing, W.M.A.; visualization, W.M.A.; supervision, C.H.S.; project administration, I.A.S.d.B.; funding acquisition, P.J.W.K.d.B., W.M.A. and J.O.M. All authors have read and agreed to the published version of the manuscript.

Funding: This research was funded by the Conselho Nacional de Desenvolvimento Científico e Tecnológico (CNPq), grant number 155885/2018-9 and by the Fundação de Amparo à Pesquisa do Estado do Rio Grande do Sul (FAPERGS), grant number 19/2551-0001988-2.

Conflicts of Interest: The authors declare no conflict of interest.

\section{References}

1. Nakamura, T.; Halada, K. Urban Mining Systems; Springer: Berlin/Heidelberg, Germany, 2015.

2. Cucchiella, F.; D'Adamo, I.; Koh, S.L.; Rosa, P. Recycling of WEEEs: An economic assessment of present and future e-waste streams. Renew. Sustain. Energy Rev. 2015, 51, 263-272. [CrossRef]

3. Wieszczycka, K.; Tylkowski, B.; Staszak, K. Metals in Wastes; De Gruyter: Berlin, Germany, 2018.

4. Echegaray, F.; Hansstein, F.V. Assessing the intention-behavior gap in electronic waste recycling: The case of Brazil. J. Clean. Prod. 2017, 142, 180-190. [CrossRef]

5. Duan, H.; Hou, K.; Li, J.; Zhu, X. Examining the technology acceptance for dismantling of waste printed circuit boards in light of recycling and environmental concerns. J. Environ. Manag. 2011, 92, 392-399. [CrossRef] [PubMed]

6. Kaya, M. Recovery of metals and nonmetals from electronic waste by physical and chemical recycling processes. Waste Manag. 2016, 57, 64-90. [CrossRef]

7. Montero, R.; Guevara, A.; dela Torre, E. Recovery of gold, silver, copper and niobium from printed circuit boards using leaching column technique. J. Earth Sci. Eng. 2012, 2, 590.

8. Cui, J.; Forssberg, E. Mechanical recycling of waste electric and electronic equipment: A review. J. Hazard. Mater. 2003, 99, 243-263. [CrossRef]

9. Hao, J.; Wang, Y.; Wu, Y.; Guo, F. Metal recovery from waste printed circuit boards: A review for current status and perspectives. Resour. Conserv. Recycl. 2020, 157, 104787. [CrossRef]

10. Nithya, R.; Sivasankari, C.; Thirunavukkarasu, A. Electronic waste generation, regulation and metal recovery: A review. Environ. Chem. Lett. 2020, 19, 1347-1368. [CrossRef]

11. Aurubis. Recycling Technology. Available online: https://www.aurubis.com/en/products--services/recycling/technology (accessed on 19 July 2021).

12. Glencore. Recycling Operations. Available online: https://www.glencore.com/what-we-do/recycling/operations (accessed on 19 July 2021).

13. Umicore. Recycling Process. Available online: https://pmr.umicore.com/en/about-us/process/ (accessed on 19 July 2021).

14. Huang, Y.-F.; Pan, M.-W.; Lo, S.-L. Hydrometallurgical metal recovery from waste printed circuit boards pretreated by microwave pyrolysis. Resour. Conserv. Recycl. 2020, 163, 105090. [CrossRef]

15. Wang, J.; Huang, Z.; Yang, D.; Zeng, X.; Chen, M.; Shu, J.; Sun, Z.; Sun, S.; Xiao, Z. A semi-scaled experiment for metals separating and recovering from waste printed circuit boards by slurry electrolysis. Process. Saf. Environ. Prot. 2021, 147, 37-44. [CrossRef]

16. Qiu, R.; Lin, M.; Ruan, J.; Fu, Y.; Hu, J.; Deng, M.; Tang, Y.; Qiu, R. Recovering full metallic resources from waste printed circuit boards: A refined review. J. Clean. Prod. 2020, 244, 118690. [CrossRef]

17. Srivastava, R.R.; Ilyas, S.; Kim, H.; Choi, S.; Trinh, H.B.; Ghauri, M.A.; Ilyas, N. Biotechnological recycling of critical metals from waste printed circuit boards. J. Chem. Technol. Biotechnol. 2020, 95, 2796-2810. [CrossRef] 
18. Dey, S.K.; Ari, V.; Das, A. Processing of electronic waste in a counter current teeter-bed separator. J. Environ. Manag. 2012, 107, 45-51. [CrossRef] [PubMed]

19. Meng, L.; Gao, J.; Zhong, Y.; Wang, Z.; Chen, K.; Guo, Z. Supergravity separation for recovering Pb and Sn from electronic waste. Sep. Purif. Technol. 2018, 191, 375-383. [CrossRef]

20. Phengsaart, T.; Ito, M.; Hamaya, N.; Tabelin, C.B.; Hiroyoshi, N. Improvement of jig efficiency by shape separation, and a novel method to estimate the separation efficiency of metal wires in crushed electronic wastes using bending behavior and "entanglement factor". Miner. Eng. 2018, 129, 54-62. [CrossRef]

21. Dias, P.; Schmidt, L.; Gomes, L.B.; Bettanin, A.; Veit, H.; Bernardes, A.M. Recycling waste crystalline silicon photovoltaic modules by electrostatic separation. J. Sustain. Metall. 2018, 4, 176-186. [CrossRef]

22. Xue, M.; Yan, G.; Li, J.; Xu, Z. Electrostatic separation for recycling conductors, semiconductors, and nonconductors from electronic waste. Environ. Sci. Technol. 2012, 46, 10556-10563. [CrossRef]

23. Jeon, S.; Ito, M.; Tabelin, C.B.; Pongsumrankul, R.; Tanaka, S.; Kitajima, N.; Saito, A.; Park, I.; Hiroyoshi, N. A physical separation scheme to improve ammonium thiosulfate leaching of gold by separation of base metals in crushed mobile phones. Miner. Eng. 2019, 138, 168-177. [CrossRef]

24. Zhu, X.-N.; Nie, C.-C.; Zhang, H.; Lyu, X.-J.; Qiu, J.; Li, L. Recovery of metals in waste printed circuit boards by flotation technology with soap collector prepared by waste oil through saponification. Waste Manag. 2019, 89, 21-26. [CrossRef]

25. Zhu, X.-N.; Zhang, Y.-K.; Zhang, Y.-Q.; Yan, Z.-Q.; Nie, C.-C.; Lyu, X.-J.; Tao, Y.-J.; Qiu, J.; Li, L. Flotation dynamics of metal and non-metal components in waste printed circuit boards. J. Hazard. Mater. 2020, 392, 122322. [CrossRef]

26. Hsu, E.; Barmak, K.; West, A.C.; Park, A.-H.A. Advancements in the treatment and processing of electronic waste with sustainability: A review of metal extraction and recovery technologies. Green Chem. 2019, 21, 919-936. [CrossRef]

27. Perkins, D.N.; Drisse, M.-N.B.; Nxele, T.; Sly, P.D. E-waste: A global hazard. Ann. Glob. Health 2014, 80, 286-295. [CrossRef]

28. Zhu, X.-N.; Nie, C.-C.; Wang, S.-S.; Xie, Y.; Zhang, H.; Lyu, X.-J.; Qiu, J.; Li, L. Cleaner approach to the recycling of metals in waste printed circuit boards by magnetic and gravity separation. J. Clean. Prod. 2020, 248, 119235. [CrossRef]

29. Speight, J.G. Handbook of Coal Analysis; John Wiley \& Sons: Hoboken, NJ, USA, 2015.

30. Wills, B.A.; Finch, J. Wills' Mineral Processing Technology: An Introduction to the Practical Aspects of Ore Treatment and Mineral Recovery; Butterworth-Heinemann: Burlington, MA, USA, 2015.

31. Mitra, S. Sample Preparation Techniques in Analytical Chemistry; John Wiley \& Sons: Hoboken, NJ, USA, 2004 ; Volume 237.

32. de Buzin, P.J.W.K.; Heck, N.C. Electrolytic recovery of tin from electronic component industrial waste. In Proceedings of the 67th ABM International Congress, Rio de Janeiro, Brazil, 31 July-3 August 2012.

33. Vergés, M.A.; Martinez, M.; Matijevié, E. Synthesis and characterization of zinc ferrite particles prepared by hydrothermal decomposition of zinc chelate solutions. J. Mater. Res. 1993, 8, 2916-2920. [CrossRef]

34. Kresse, R.; Baudis, U.; Jäger, P.; Riechers, H.H.; Wagner, H.; Winkler, J.; Wolf, H.U. Barium and barium compounds. Ullmann's Encycl. Ind. Chem. 2000. [CrossRef]

35. Oskarsson, A.B. Handbook on the Toxicology of Metals; Elsevier: Amsterdam, The Netherlands, 2015; pp. 625-634.

36. Phengsaart, T.; Ito, M.; Azuma, A.; Tabelin, C.B.; Hiroyoshi, N. Jig separation of crushed plastics: The effects of particle geometry on separation efficiency. J. Mater. Cycles Waste Manag. 2020, 22, 787-800. [CrossRef]

37. Phengsaart, T.; Ito, M.; Kimura, S.; Azuma, A.; Hori, K.; Tanno, H.; Jeon, S.; Park, I.; Tabelin, C.B.; Hiroyoshi, N. Development of a restraining wall and screw-extractor discharge system for continuous jig separation of mixed plastics. Miner. Eng. 2021, 168, 106918. [CrossRef]

38. Devasahayam, S.; Raju, G.B.; Hussain, C.M. Utilization and recycling of end of life plastics for sustainable and clean industrial processes including the iron and steel industry. Mater. Sci. Energy Technol. 2019, 2, 634-646. [CrossRef]

39. Schlesinger, M.E. Aluminum Recycling; CRC press: Boca Raton, FL, USA, 2006.

40. Dutta, S.K.; Lodhari, D.R. Extraction of Nuclear and Non-Ferrous Metals; Springer: Berlin/Heidelberg, Germany, 2018.

41. Vignes, A. Extractive Metallurgy 2: Metallurgical Reaction Processes; John Wiley \& Sons: Hoboken, NJ, USA, 2013. 